\title{
Multifunction Finishing of Cellulose Based Fabrics via 3- Chloro-2-Hydroxypropyl Trimethyl Ammonium Chloride (Quat-188) and Silver Nanoparticles (AgNPs) to Improve its Dyeability and Antibacterial
}

\author{
Heba A. Ghazal ${ }^{1(\mathbb{D})}$, Ahmed A.M. El-Masry ${ }^{2(\mathbb{D})}$, Rehab M. Mosaad ${ }^{3,4 . *(\mathbb{D})}$ \\ 1 Faculty of Applied Arts, Textile Printing, Dyeing and Finishing Department, Benha University, Benha, Egypt; \\ drheba_ghazal@yahoo.com (H.A.G.) ; \\ 2 Department of Physics, Women's College Ain Shams University, Cairo, Egypt; masry747@gmail.com (A.A.M.E.M.); \\ 3 Department of Biology, College of Science, Majmaah University, Majmaah 11952, Saudi Arabia; rehab.m@mu.edu.sa \\ (R.M.M.); \\ 4 Department of Zoology, Women's College, Ain Shams University, Egypt; rehabmosaad@ aol.com (R.M.M.); \\ * Correspondence: rehab.m@mu.edu.sa;
}

Scopus Author ID 57196315735

Received: 20.11.2020; Revised: 12.12.2020; Accepted: 14.12.2020; Published: 16.12.2020

\begin{abstract}
The main goal of this study is to modify cotton as cellulose-based fabrics through cationization to improve its dyeing with acid dyes and its antibacterial. Quat-188 was applied to cotton to prepare cationized cotton, overcoming the negative charges between cotton and acid dyes during the dyeing process without using any electrolyte via the pad-dry-cure method. Then the cationized cotton fabrics were treated with the prepared silver nanoparticles to improve their antibacterial properties. The untreated and treated cotton fabrics were dyed with two acid dyes Acid Brilliant Blue PB 100\% (acid blue 25; AB25) and Acid Metanil Yellow MT 100\% (acid yellow 36) at concentrations of 2\%, 4\%, and $6 \%$ of by exhaust method. Colour strength, color, and washing fastness of untreated and treated cotton fabrics were studied. Antibacterial properties of fabrics were also evaluated against $S$. aureus and $E$. coli by using the disk diffusion method. Dyeing properties showed that the treated cotton fabrics significantly improved color strength and fastness properties (light, washing, perspiration, and rubbing). Also, the antibacterial properties of treated cotton fabrics showed antibacterial activity towards tested bacteria. This study reveals that modified cotton fabrics via cationization with Quat-188 and AgNPs have multifunctional properties from their ability for acid dyes and their higher antibacterial activity towards Gram-positive and Gram-negative bacteria that is can be used in many applications.
\end{abstract}

Keywords: cotton fabrics; modification; acid dyes; color; fastness properties; antibacterial.

(C) 2020 by the authors. This article is an open-access article distributed under the terms and conditions of the Creative Commons Attribution (CC BY) license (https://creativecommons.org/licenses/by/4.0/).

\section{Introduction}

Cotton fabrics is a cellulosic polymer with a cellobiose repeating unit in its structure. It is very popular among other natural fabrics due to their unique properties. It is soft, breathable, and wear comfort. On the other hand, it has low UV protective, hygroscopic nonconductive so that its application is limited without modification [1-3]. Cotton fabrics contain three hydroxyl groups on their structure can form partial negative charge on their surface in an aqueous medium [4].

Most of the dyes used for cotton fabrics have ionic nature and cause electrostatic repulsion with negative cotton charges [5]. This repulsion between dyes and fabrics reduces 
the dye exhaustion from dye bath into the fabrics, which can be overcome. The addition of salt can neutralize these negative charges on the fabric's surface to overcome this repulsion and increase the dye exhaustion [6-8]. The addition of salts does not allow all dyes to penetrate inside the fabric surface, which causes environmental pollution from the washing process that carries the remaining dyes and salt into rivers and oceans [9-13].

Acid dyes are common dyes for proteinic fabrics such as wool, silk, and polyamide [14-16]. They are not used for cellulosic based fabrics like reactive and direct dyes due to lack of affinity to these fabrics and electrostatic repulsion [17-19]. Acid dyes cheaper than reactive dyes and cover a full-color range with bright shades. Many researchers in literature report on the direction towards a modification of cotton fabrics to enhance their affinity towards acid dyes [20-22].

Cationized cotton fabrics showed higher exhaustion of reactive dyes and enhanced color properties were reported in many research works such as by using Quat-188 [23], chitosan-poly(propylene imine) dendrimer hybrid [24-29], Glycidyl trimethyl ammonium chloride [21], combination with mercerization [30], combination with plasma [31] and Poly [styrene-butyl acrylate-(P-vinyl benzyl trimethyl ammonium chloride] [32,33].

Silver metal and its ions have broad-spectrum antibacterial activity on S. aureus and $E$. coli bacteria. Silver ions can be linked to the outer bacterial cell and cell wall through their interaction with enzyme thiol groups and proteins. Then it causes bacterial cell death. Thus silver metal and their compounds are effective in wound infections [34-44].

In this study, cotton fabrics were modified using Quat-188 to alter the negative charges and introduce cationic sites to increase acid dyes' affinity towards these fibers. Then, these fabrics were treated with silver nanoparticles (AgNPs) to increase their antibacterial activity. The modified cotton fabrics were dyes using acid dyes via the exhaust method. The finished and dyed cotton fabrics were characterized by color properties (color strength, wash fastness, perspiration fastness, Rubbing, and lightfastness) and antibacterial activity evaluation from the disk diffusion method.

\section{Materials and Methods}

\subsection{Materials.}

EL-Nasr Company supplied the fabric of $100 \%$ Cotton for Spinning, Weaving, and Dyeing, El-Mehalla Elkubra, Egypt, with 36 yarn/cm warp, 30 yarn $/ \mathrm{cm}$ weft, and $150 \mathrm{~g} / \mathrm{m}^{2}$ weight. The fabric was further scoured in the laboratory at $100^{\circ} \mathrm{C}$ for $60 \mathrm{~min}$ using a solution containing $2 \mathrm{~g} / \mathrm{l}, \mathrm{Na}_{2} \mathrm{CO}_{3}$, and $1 \mathrm{~g} / \mathrm{l}$, Egyptol (non-ionic wetting agent based on ethylene oxide condensate). The cationized agent 3-chloro-2-hydroxypropyl trimethyl ammonium chloride (Quat-188) with a concentration of 65\% was purchased from Sigma Aldrich, USA. The Acid dyes used were Acid Brilliant Blue PB 100\% (acid blue 25) and Acid Metanil Yellow MT $100 \%$ (acid yellow 36) supplied by the Archroma. Silver nitrate supplied from Fischer Scientific co. Polyvinyl alcohol with 115,000 M. wt., 1700-1800 polymerization, 25-32 cP viscosity and hydrolysis 98-99 mole\%) was purchased from Alpha chemika, India. Glucose was purchased from Aldrich Chemical. Other chemicals are used in analytical grade and used without further purification. 


\subsection{Methods.}

\subsubsection{Modification of cotton fabrics.}

Cationic modification of the cotton fabric was performed by using the pad-dry-cure method. The experimental procedure adopted was as follows: 3-Chloro-2-hydroxypropyl trimethyl ammonium chloride (Quat-188) (20 g/l) was mixed with $20 \mathrm{~g} / \mathrm{l}$ of sodium hydroxide $(50 \%)$ solution at a 1:2 molar ratio. The cotton fabric was padded in this mixture at $100 \%$ wet pick-up. Then cotton fabric dried at $40{ }^{\circ} \mathrm{C}$ for $10 \mathrm{~min}$ and cured at $120{ }^{\circ} \mathrm{C}$ for $3 \mathrm{~min}$. Thus, treated cotton several times washing have dined with acetic acid (1\%) and water followed by drying at normal conditions. The main role of sodium hydroxide is converting Quat-188 into active epoxide, as shown in Scheme. 1. As a result, the cotton fabric has cationic dye sites covalently bounded to the cellulose. Due to these positively charged dye sites on the cotton fabric, it became possible to apply the anionic Acid dyes onto the cotton fabric without using any electrolyte.

\subsubsection{Preparation of silver nanoparticles (AgNPs).}

Different concentrations of silver nitrate $\left(\mathrm{AgNO}_{3}\right)(0.001 \mathrm{M}, 0.01 \mathrm{M}, 0.1 \mathrm{M})$ were dissolved into an aqueous solution of PVA $(3 \mathrm{~g} / 100 \mathrm{ml})$ in the presence of glucose $(0.15 \mathrm{~g} / 100$ $\mathrm{ml}$ ) for every experiment to overcome the oxidation of silver nitrate into silver oxide. The reduction time was $72 \mathrm{~h}$. at room temperature $[45,46]$.

\subsubsection{Finishing of treated cotton fabrics with silver nanoparticles (AgNPs).}

The treated cotton fabric was padded in a silver nanoparticles suspension with different concentrations of $\mathrm{AgNO}_{3}(0.001 \mathrm{M}, 0.01 \mathrm{M}$, and $0.1 \mathrm{M}$ solution) that corresponds $0.034 \mathrm{~g} / \mathrm{L}$, $0.34 \mathrm{~g} / \mathrm{L}$, and $3.4 \mathrm{~g} / \mathrm{L} \mathrm{AgNPs}$, respectively. The fabric was then squeezed to a wet pick-up of ca $100 \%$ and drying at $80^{\circ} \mathrm{C}$ for $5 \mathrm{~min}$. Then it was padded in an aqueous solution containing glyoxal $(50 \mathrm{~g} / \mathrm{L})$ and aluminum sulfate $\mathrm{Al}_{2}(\mathrm{SO} 4)_{3}(20 \mathrm{~g} / \mathrm{L})$. Then it squeezed to a wet pick-up of ca $100 \%$, followed by drying at $80^{\circ} \mathrm{C}$ for $5 \mathrm{~min}$ and thermo fixation at $120^{\circ} \mathrm{C}$ for $3 \mathrm{~min}$. Finally, the sample was washed several times with cold water and dried at ambient conditions.

\subsubsection{Dyeing of unmodified and modified cotton fabrics.}

The dyeing of the unmodified and the modified cotton fabrics with the Acid dyes was carried out with exhaust method using high-temperature dyeing machine at $100 \circ \mathrm{C}$ for $60 \mathrm{~min}$ keeping the liquor ratio at 40:1. The $\mathrm{pH}$ of the dye bath was kept neutral around 7. The unmodified and the modified cotton fabrics were dyed with the shade depths of $2 \%, 4 \%$, and 6\% using Acid Brilliant Blue PB 100\% (acid blue 25) and Acid Metanil Yellow MT 100\% (acid yellow 36) dyes. After the dyeing, the dyed samples were washed with the detergent $2 \mathrm{~g} / \mathrm{l}$ at $70{ }^{\circ} \mathrm{C}$ for $15 \mathrm{~min}$.

\subsection{Testing and analysis.}

\subsubsection{FT-IR spectra.}

The FT-IR spectra of the samples were recorded using an FT-IR spectrophotometer (JASCO FT-IR-6100) using the KBr pellet disk method for transmittance measurements region of $4000-400 \mathrm{~cm}-1$ with spectra resolution of $4 \mathrm{~cm}^{-1}$. 


\subsubsection{Thermogravimetric analysis (TGA).}

Thermogravimetric analysis (TGA) was performed at a temperature starting from $25^{\circ} \mathrm{C}$ to $600{ }^{\circ} \mathrm{C}$ under an inert nitrogen atmosphere with a heating rate of $10{ }^{\circ} \mathrm{C} \mathrm{min}^{-1}$ using the instrument: SDT Q600 V20.9 Build 20, USA.

\subsubsection{Tensile strength.}

The tensile strength of the fabric sample was determined by the ASTM Test Method D5035. A Q-Test 1/5 tensile tester. Three specimens for each treated fabric were tested in the warp direction, and the average value was recorded to represent the fabric breaking load (Lb).

\subsubsection{Ultraviolet-visible (UV-vis) spectra.}

UV-Vis spectra have been used to confirm the formation of silver nanoparticles in colloidal solution.

\subsubsection{Transmission Electron Microscopy (TEM).}

The shape and size of AgNPs were practically obtained by using TEM; JEOL-JEM1200. Specimens for TEM measurements were prepared by placing a drop of colloidal solution on 400 mesh copper grids coated by an amorphous carbon film and evaporating the solvent in the air at room temperature. The average diameter of the prepared AgNPs was determined from the diameter of 100 nanoparticles found in several arbitrarily chosen areas in enlarged microphotographs.

\subsubsection{Scanning electron microscopy (SEM).}

Microscopic investigation of the fabric sample was carried out using a Philips XL30 scanning electron microscope (SEM) equipped with a LaB6 electron gun and a PhilipsEDAX/DX4 energy-dispersive spectroscopy (EDS). Images were taken at different magnifications (from 1509 to 30009), using the scanning electron microscope (SEM) following the images' clarity. Fabric samples were fixed with carbon glue and metalized by gold vapor deposition to record images.

\subsubsection{X-ray diffraction.}

X-ray diffraction patterns of samples were recorded on an STOE STADI P Transmission X-ray powder diffractometer system by monitoring the diffraction angle from 10 to 80 (2h) using monochromatized $\mathrm{Cu} \mathrm{Ka}(\mathrm{k}=1.54051 \AA)$ radiation.

\subsubsection{Colour measurements and fastness properties.}

The dyed samples were tested according to AATCC and ISO standards. The color strength values (K/S) were determined using CIE Lab: D-65 10 standard. The ISO-CO6 D1M was used to determine the color-fastness to laundering. The color-fastness to laundering, colorfastness to perspiration, and color-fastness to rubbing was measured using AATCC-15, AATCC-8, and AATCC-16 standards. Comparison of cotton and wool fabrics with test fabric has been made by using gray-scale. Scales are varying from 1-8, corresponding to very poor to outstanding values. 
2.3.9. Evaluation of Antibacterial activity.

\subsubsection{Materials.}

Two bacterial strains were E. coli ATCC 11229 (Gram-negative) and S. aureus ATCC 6538 (Gram-positive). These bacterial strains were selected as test cells because they are the most frequent bacteria in the wounds. Bacterial inoculants were prepared at $37 \mathrm{oC}$ for $24 \mathrm{hrs}$.

\subsubsection{Test method.}

The antibacterial and antifungal activities of treated and dyed samples were evaluated using the disk diffusion method on an agar plate [47,48]. Briefly, $1 \mathrm{~cm}$ diameter of cotton fabrics was cut and incubated in $10 \mathrm{ml}$ nutrient agar containing $10 \mu 1$ microbe at $37{ }^{\circ} \mathrm{C}$ for 24 hrs. h, after which the diameter of the inhibition zone was measured and recorded.

\section{Results and Discussion}

\subsection{Chemical modification of cotton fabrics.}

There is an increasing interest in tailoring cotton fabrics into biomedical applications. Hiren cotton fabrics were subjected to two different chemical modification strategies to improve further treatment for antibacterial and other biomedical applications. In the first strategy, cotton fabrics were modified via cationization by using Quat-188 in the presence of $\mathrm{NaOH}$ through epoxy intermediate formation (2,3-dihydroxy propyl trimethyl ammonium chloride) that can be easily attacked by cotton hydroxyl groups as shown in scheme 1 .

\subsection{Preparation and characterization of silver nanoparticles.}

Silver nitrate can be reduced to Silver nanoparticles by using PVA in the presence of glucose. Silver ions carry positive charges that can bind with PVA hydroxyl groups that carry negative ions and cause a change of PVA colloidal solution color upon the addition of $\mathrm{AgNO}_{3}$ from colorless- pale yellow to brownish-yellow. Then glucose can react with $\mathrm{Ag}^{+} / \mathrm{PVA}$ complex to form $\mathrm{Ag}^{0}$. Finally, $\mathrm{Ag}^{0}$ can be easily separated from the $\mathrm{Ag}^{+} / \mathrm{PVA}$ complex under ultrasonic radiation $[49,50]$.

Figure 1 shows the UV absorption spectra of colloidal silver nanoparticles formed from $\mathrm{AgNO}_{3}$ molar concentration at $\left.0.01 \mathrm{M}\right)$ and PVA $(3 \mathrm{~g} / 100 \mathrm{ml})$. AgNPs show a homogeneous narrow absorption band at $428 \mathrm{~nm}$. No absorption has been observed at wavelengths more than $500 \mathrm{~nm}$. This confirmed the formation of silver nanoparticles with a complete reduction of $\mathrm{AgNO}_{3}$.

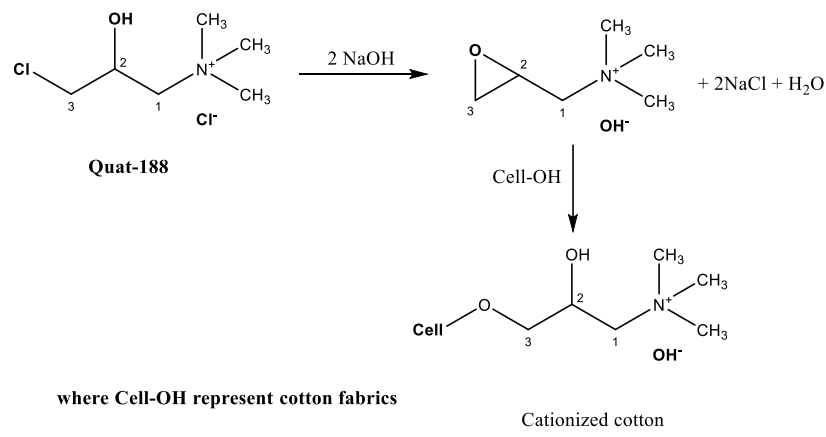

Scheme 1. Cationization of cotton fabrics. 


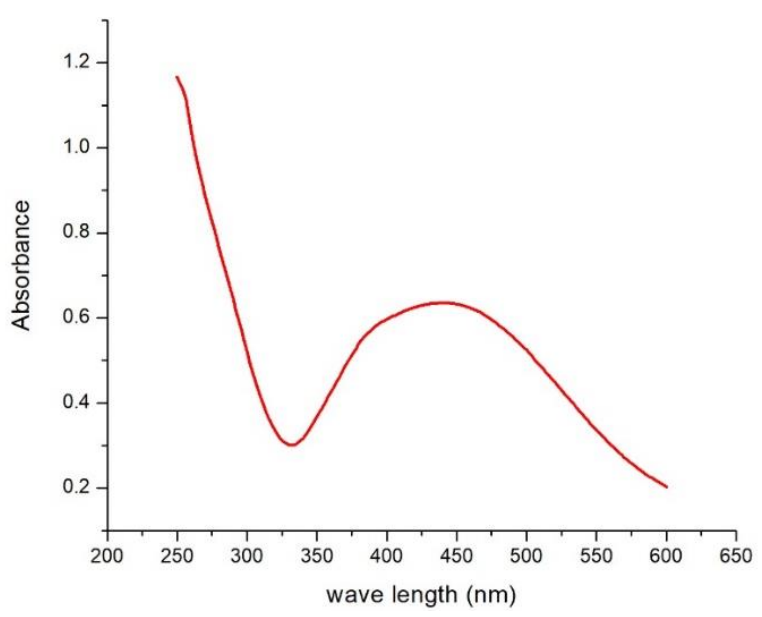

Figure 1. UV spectra of the silver nanoparticles (AgNPs) formed at silver nitrate concentration $0.01 \mathrm{M}$ and 3 wt $\%$ PVA, at RT for $72 \mathrm{~h}$.

The crystal structure of Ag nanoparticles was confirmed by using X-ray diffraction (XRD). Figure 2 shows an XRD diagram of AgNPs at 0.01 M concentration. Figure 2 shows characteristic peaks at 38.1, 44.3, 64.4, and 78.0, confirming the AgNPs structure. [51].

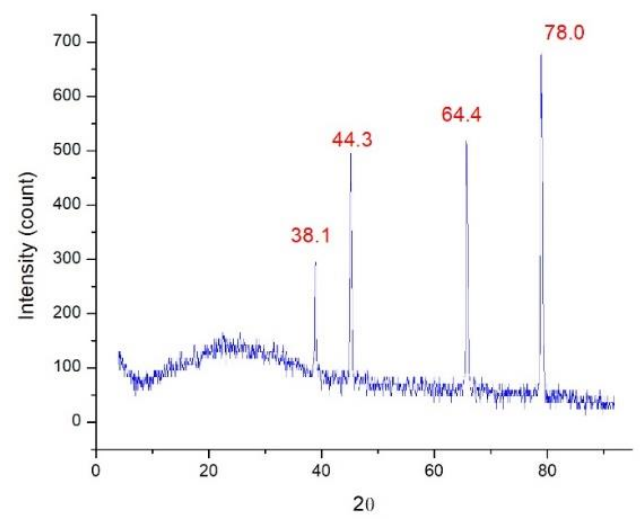

Figure 2. X-ray diffraction of silver nanoparticles (AgNPs) from $0.01 \mathrm{M} \mathrm{AgNO}_{3}$ and $3 \mathrm{wt} \% \mathrm{PVA}$, at RT for 72 $h$.

The shape and size of Ag nanoparticles were illustrated by using transmission electron microscopy (TEM) as shown in Figure 3. Silver nanoparticles formed from silver nitrate molar concentration $(0.01 \mathrm{M})$ show well disperse and semi-spherical shapes with average particle size from 15-25 nm, as shown in Figure 3.

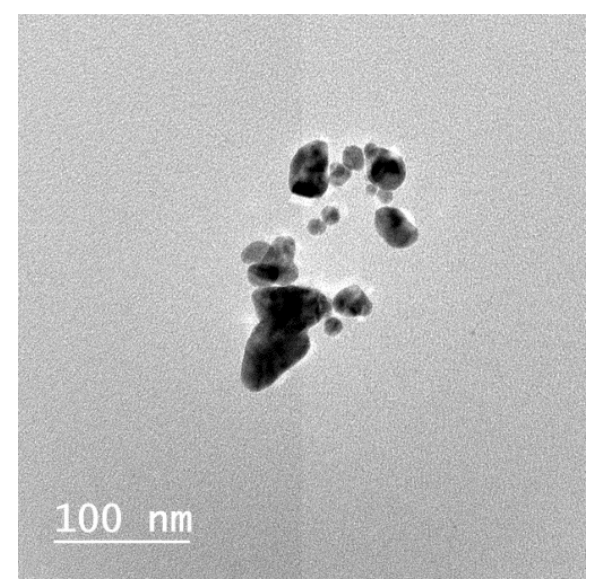

Figure 3. Transmission electron microscopy (TEM) of AgNPs from $0.01 \mathrm{M} \mathrm{AgNO}_{3}, 3 \mathrm{wt} \% \mathrm{PVA}$, at RT for 72 $h$. 


\subsection{Finishing of cotton fabrics with silver nanoparticles.}

The morphology of cotton fabrics (untreated, Ag nanoparticles treated, dyed with acid dye, and treated with Ag nanoparticles) were studied by scanning electron microscopy (SEM) as shown in Figure 4.

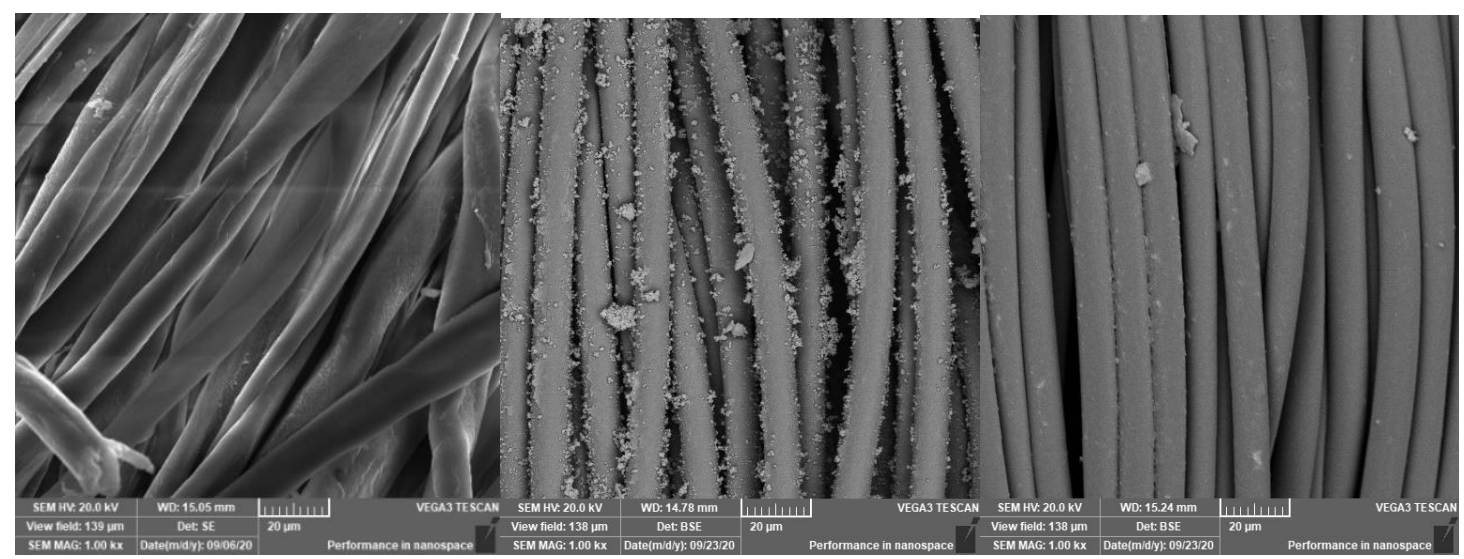

Figure 4. SEM images of cotton fabrics (a) untreated, (b) treated with Ag nanoparticles, and (c) dyed with acid dye and treated with silver nanoparticles.

Figure 4 confirmed the presence of fine particles from Ag nanoparticles, distributed uniform inside and outside the nanofibers after treatment with AgNPs (Figure 4b). These nanoparticles sub disappeared on the treated dyed samples, which reflect the major effect of dyeing on the overall process as shown in (Figure 4c), compared with untreated fabric (Figure $4 a)$.
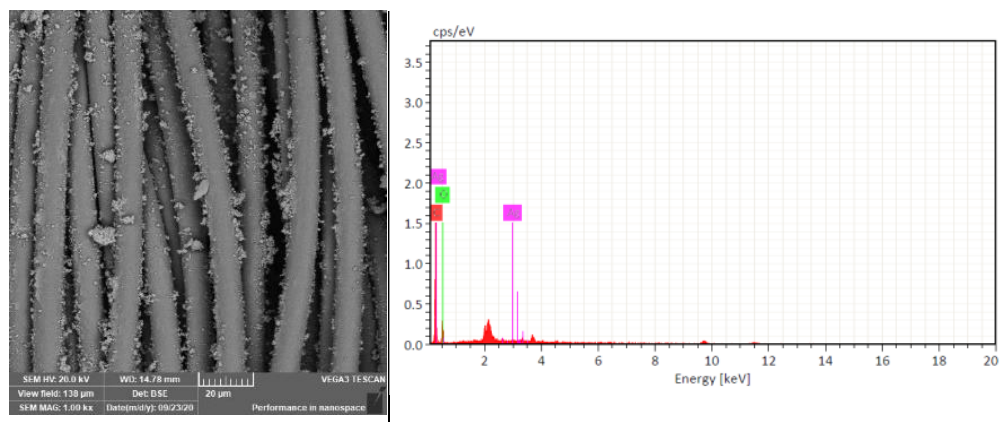

\begin{tabular}{|c|c|c|} 
Element & Weight \% & Atomic \% \\
\hline $\mathrm{C} \mathrm{K}$ & 56.09 & 64.62 \\
\hline $\mathrm{N} \mathrm{K}$ & 2.59 & 2.45 \\
\hline $\mathrm{O} \mathrm{K}$ & 27.07 & 26.07 \\
\hline $\mathrm{NaK}$ & 5.77 & 3.74 \\
\hline $\mathrm{ClK}$ & 6.31 & 2.96 \\
\hline $\mathrm{AgL}$ & 2.17 & 0.28
\end{tabular}

Figure 5. Electron dispersed X-ray (EDX) analysis of cotton fabrics treated with silver nanoparticles.

Figure 5 shows the electron dispersed X-ray analysis (EDX) of cotton fabrics treated with Ag nanoparticles and its SEM image. EDX analysis (Figure 5) confirmed the presence of AgNPs on the treated cotton fabric's surface (Ag wt.\% is 2.17, and atomic \% is 0.28).

\subsection{Dyeing of Ag nanoparticles treated cotton fabrics with acid dyes.}

\subsubsection{Colour strength.}

Colour strength is used as an important parameter to test the quality of fabrics towards dyeing. As shown from Figure 6, the color yield values of cationized cotton fabric samples are higher than that for uncationized fabric due to the electrostatic attraction between the surface of cotton fabrics and Acid dye molecules, where the cationized surface of cotton fabric attracts the anionic acid dye molecules. A higher number of negatively charged dye molecules are attracted towards the fabric surface, followed by enhanced absorption and dye uptake resulting 
in deeper shades and higher color yield values. In addition, it can be observed in Figure 6, that the K/S values of unmodified samples dyed with acid blue 25 are lower than the samples dyed with acid yellow 36. It can also be observed that the K/S values of the cationized sample dyed with acid blue 25 are higher than that of cationized samples dyed with acid yellow 36 due to the acid dye structure.

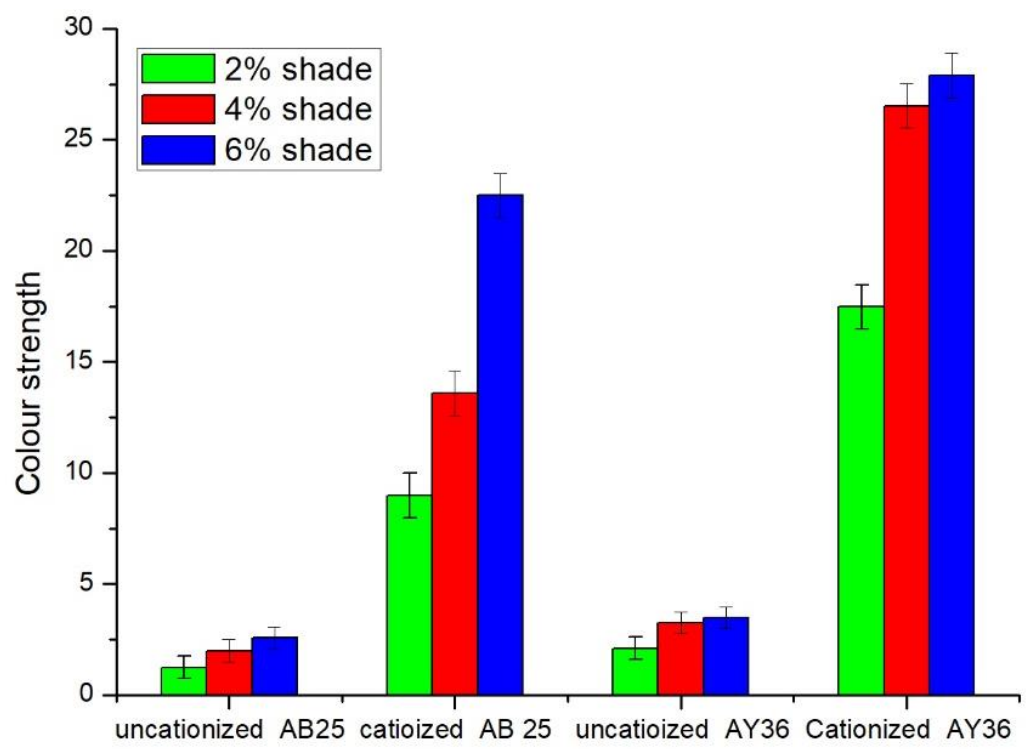

Figure 6. Colour strength values for uncationized and cationized dyed cotton samples with two acid dyes, acid blue 25 (AB 25) and acid yellow 36 (AY 36).

\subsubsection{Washing fastness.}

Tables 1 and 2 show the washing fastness of uncationized and cationized cotton fabrics dyed with acid blue 25 and acid yellow 36. The results show that the washing fastness of uncationized fabrics dyed with the acid dyes is better in case of color change than that of cationized fabrics due to the removal of unfixed dye from the cationized dyed samples.

Table 1. Washing fastness of cationized and uncationized cotton fabrics dyed with acid blue 25 .

\begin{tabular}{l|c|c|c|c} 
& Shade depth & \multirow{2}{*}{ Shade change } & \multicolumn{2}{|c}{ Staining } \\
\cline { 4 - 5 } & & & Cotton & Wool \\
\hline Uncationized cotton fabric & $2 \%$ & 4 & $4-5$ & 4 \\
\cline { 2 - 5 } & $4 \%$ & $3-4$ & $4-5$ & $3-4$ \\
\cline { 2 - 5 } & $6 \%$ & $3-4$ & $4-5$ & $3-4$ \\
\hline \multirow{3}{*}{ Cationized cotton fabric } & $2 \%$ & $3-4$ & $4-5$ & $3-4$ \\
\cline { 2 - 5 } & $4 \%$ & $3-4$ & $4-5$ & $3-4$ \\
\cline { 2 - 5 } & $6 \%$ & $3-4$ & $4-5$ & $3-4$
\end{tabular}

Table 2. Washing fastness of cationized and uncationized cotton fabrics dyed with acid yellow 36 .

\begin{tabular}{l|c|c|c|c} 
& Shade depth & Shade change & \multicolumn{2}{|c}{ Staining } \\
\cline { 4 - 5 } & & & Cotton & Wool \\
\hline Uncationized cotton fabric & $2 \%$ & 4 & $3-4$ & 3 \\
\cline { 2 - 5 } & $4 \%$ & 4 & $3-4$ & 3 \\
\cline { 2 - 5 } & $6 \%$ & 4 & $3-4$ & 3 \\
\hline \multirow{2}{*}{ cationized cotton fabric } & $2 \%$ & $2-3$ & $3-4$ & 3 \\
\cline { 2 - 5 } & $4 \%$ & 2 & $3-4$ & $2-3$ \\
\cline { 2 - 5 } & $6 \%$ & 2 & 3 & $2-3$
\end{tabular}

\subsubsection{Perspiration fastness.}

Table 3 shows the results of color change and staining exhibited by uncationized and cationized fabrics upon contact with the acid perspiration solution. The results show that 
colorfastness to perspiration of uncationized samples and cationized samples is very good pertaining to the color change. However, in staining, the cationized dyed samples have poor fastness compared to uncationized samples. This can be attributed to the higher shade depth that can cause the removal of a higher number of dye molecules during interaction with perspiration solution stain the adjacent white fabric.

Table 3. Perspiration fastness of cationized and uncationized cotton fabrics dyed with acid yellow 36; SS stands for cr change, and $\mathrm{S}$ represents staining.

\begin{tabular}{l|l|l|l|l|l|l|l|l}
\multirow{3}{*}{ Shade depth } & \multicolumn{2}{l}{ Uncationized } & \multicolumn{2}{l|}{ cationized } & \multicolumn{2}{l|}{ Uncationized } & \multicolumn{2}{c}{ cationized } \\
\cline { 2 - 9 } & Blue 25 & \multicolumn{2}{l}{ Blue 25 } & \multicolumn{2}{l}{ Yellow 36 } & \multicolumn{2}{l}{ Yellow 36 } \\
\cline { 2 - 9 } & CC & S & CC & S & CC & S & CC & S \\
\hline $2 \%$ & $4-5$ & $4-5$ & $4-5$ & 4 & $4-5$ & 4 & $4-5$ & $3-4$ \\
\hline $4 \%$ & $4-5$ & $4-5$ & $4-5$ & 4 & $4-5$ & 4 & $4-5$ & $2-3$ \\
\hline $6 \%$ & $4-5$ & $4-5$ & $4-5$ & 4 & $4-5$ & 4 & $4-5$ & $2-3$
\end{tabular}

\subsubsection{Rubbing fastness.}

Table 4 shows the rubbing fastness of cationized and uncationized samples. The results show that dry rubbing fastness of both cationized and uncationized fabric samples dyed with acid blue 25 and acid yellow 36 is good to excellent. The Acid dyes usually do not have an affinity towards cotton fabrics, so apparently, the acid dye molecules would not retain or stay onto the cotton fabrics. So cotton fabrics have a minimal affinity towards acid dyes. As a result, the dye hardly comes off in case of dry rubbing, while during wet rubbing, minimal staining has been noticed in case of deep shades.

Table 4. Rubbing fastness of cationized and uncationized cotton fabrics dyed with acid yellow 36.

\begin{tabular}{l|c|c|c|c|c|c|c|c}
\multirow{3}{*}{ Shade depth } & Uncationized & \multicolumn{2}{c|}{ Cationized } & \multicolumn{2}{c|}{ Uncationized } & \multicolumn{2}{c}{ cationized } \\
\cline { 2 - 9 } & \multicolumn{2}{|c|}{ Blue 25 } & \multicolumn{2}{c|}{ Blue 25 } & \multicolumn{2}{c}{ Yellow 36 } & \multicolumn{2}{c}{ Yellow 36 } \\
\cline { 2 - 9 } & Dry & Wet & Dry & Wet & Dry & Wet & Dry & Wet \\
\hline $2 \%$ & $4-5$ & $4-5$ & $4-5$ & 4 & $4-5$ & 4 & 4 & $3-4$ \\
\hline $4 \%$ & $4-5$ & $4-5$ & $4-5$ & 4 & $4-5$ & $4-5$ & $4-5$ & $3-4$ \\
\hline $6 \%$ & $4-5$ & $4-5$ & $4-5$ & $3-4$ & $4-5$ & 4 & $4-5$ & 4
\end{tabular}

\subsubsection{Light fastness.}

Table 5 shows the light fatness of uncationized and cationized fabric fabrics. The results show that the light fastness of uncationized samples is better than that of cationized fabrics. This is so because of the pale shade on uncationized fabrics and a darker shade on cationized fabrics. As there is a small number of dye molecules on uncationized fabric, light on the lighter shade will be less compared to the darker shades exhibiting the relatively less fastness to light of the cationized fabric fabrics. The lightfastness of dyed fabrics depends on dye structure and resonance in the dye molecules. The difference in the light fastness can be due to the shade depth.

Table 5. Lightfastness of cationized and uncationized cotton fabrics dyed with acid yellow 36 .

\begin{tabular}{l|l|l|l|l}
\multirow{2}{*}{ Shade depth } & Uncationized & cationized & Uncationized & cationized \\
\cline { 2 - 5 } & Blue 25 & Blue 25 & Yellow 36 & Yellow 36 \\
\hline $2 \%$ & 4 & $3-4$ & $4-5$ & 4 \\
\hline $4 \%$ & 4 & $3-4$ & 4 & $3-4$ \\
\hline $6 \%$ & 4 & $3-4$ & $4-5$ & $3-4$
\end{tabular}

\subsection{Antibacterial assay.}

The antibacterial activity of the cotton samples treated with Ag nanoparticles and dyed with two acid dyes (named blue 25 and yellow 36 as mentioned before) was evaluated against 
the two most frequent bacterial strains, $S$. aureus as Gram-positive bacteria and E. coli as Gramnegative bacteria. Figure 7 shows the antibacterial activity of dyed cotton fabrics at different dye concentrations from 1 to $6 \mathrm{wt}$. \% [52].

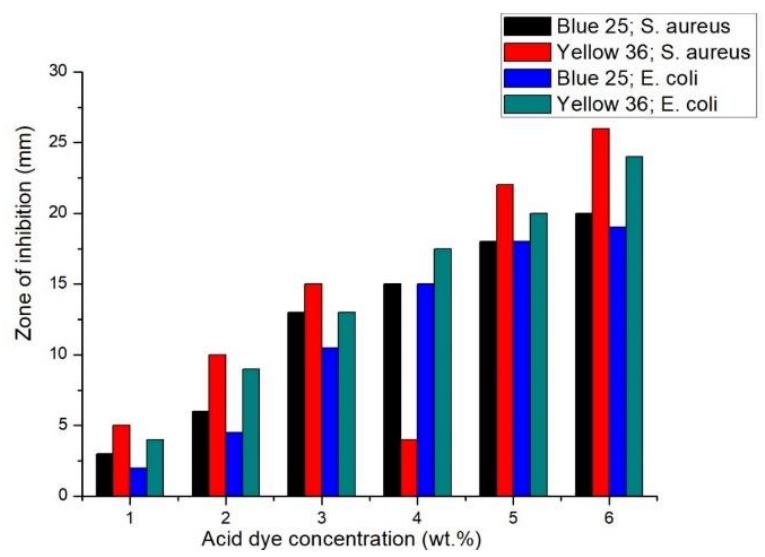

Figure 7. Antibacterial activity of cotton fabrics treated with Ag nanoparticles and dyed with two acid dyes, blue 25 and yellow 36, at different dye concentrations.

Figure 7 shows that the two-dyes' antibacterial activity regularly increased as its concentration increased from $1 \%$ to $6 \mathrm{wt} . \%$. This confirms that acid dyes also have antibacterial activity. Also, the dye showed better efficiency against $S$. aureus as Gram-positive bacteria than $E$. coli as negative bacteria because of the structure of its cell wall $[53,54]$.

Figure 8 shows the effect of washing durability of dyed fabrics on its antibacterial activity after 25 times wash fastness. The durability of the washing of these antibacterial functions depends on the bonding between acid dyes and fabrics.

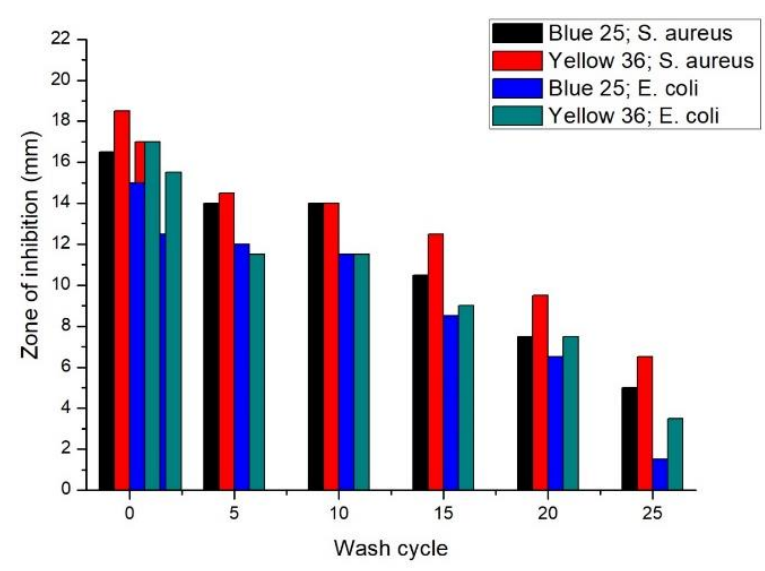

Figure 8. Effect of washing durability of two acid dyes (blue 25 and yellow 36) dyed cotton fabrics on antibacterial activity.

Figure 8 , shows the effect of washing durability of cotton fabrics dyed with two acid dyes on antibacterial activity. The results show that the dyed fabrics have antibacterial activity against Gram-positive and Gram-negative bacteria after 25 washing cycles. The bonds between fibers and dyes through chemical bonding that cause wash fastness of its antibacterial functions.

\section{Conclusions}

The cotton fabrics treated with quat- 88 provide cationic dye sites which can be dyed with the anionic Acid dyes without using any electrolyte. Besides, cotton fabrics are treated 
with Ag nanoparticles to increase their antibacterial activity. The color yield and fastness properties for wash, perspiration, and light are evaluated for modified and unmodified cotton fabrics. The washing fastness, crocking fastness, perspiration fastness, and light fastness properties of unmodified cotton fabric is better than that of unmodified cotton fabric because of low color yield. This was so because the Acid dyes have a very low affinity towards the cellulosic fabrics. However, it is found that the color yield of modified fabric is far better than unmodified fabric due to ionic attraction between the positively charged fabric and anionic dye molecule. This shows that the maximum exhaustion of the Acid dyes can be done through modification of cotton fabrics. Treated and dyed cotton fabrics showed high antibacterial activity towards Gram-positive and Gram-negative bacteria with an enhancement of dyeing properties of cotton fabrics towards acid dyes (blue 25 and yellow 36).

\section{Funding}

This research received no external funding.

\section{Acknowledgments}

This research has no acknowledgment.

\section{Conflicts of Interest}

The authors declare no conflict of interest.

\section{References}

1. Bhattacharjee, S.; Macintyre, C.R.; Wen, X.; Bahl, P.; Kumar, U.; Chughtai, A.A.; Joshi, R. Nanoparticles incorporated graphene-based durable cotton fabrics. Carbon 2020, 166, 148-163, https://doi.org/10.1016/j.carbon.2020.05.029.

2. El-Bisi, M.K.; Ibrahim, H.M.; Rabie, A.M.; Elnagar, K.; Taha, G.M.; El-Alfy, E.A. Super hydrophobic cotton fabrics via green techniques. Der Pharma Chemica 2016, 8, 57-69.

3. Farag, S.; Asker, M.M.S.; Mahmoud, M.G.; Ibrahim, H.; Amr, A. Comparative study for bacterial cellulose production Using Egyptian Achromobacter sp. Research Journal of Pharmaceutical, Biological and Chemical Sciences 2016, 7, 954-969.

4. Roy Choudhury, A.J.A.J.O.R. Coloration of cationized cellulosic fibers-a review. AATC Journal of Research 2014, 1, 11-19.

5. Shahin, M.J.I.J.O.E.R. Applications. The influence of cationization on the dyeing performance of cotton fabrics with direct dyes. Journal of Engineering Research and Applications 2015, 5, 62-70.

6. Park, S.; Choi, H.-M.J.C.C.T. Microwave-Mediated Rapid Oxidation and Cationization of Cotton Cellulose. Cellulose Chemistry And Technology 2018, 52, 311-322.

7. Ru, J.; Qian, X.; Wang, Y.J.S.r. Low-Salt or Salt-Free Dyeing of Cotton Fibers with Reactive Dyes using Liposomes as Dyeing/Level-Dyeing Promotors. Nature 2018, 8, 1-9, https://doi.org/10.1038/s41598-01831501-7.

8. Farag, S.; Ibrahim, H.M.; Amr, A.; Asker, M.S.; El-Shafai, A. Preparation and characterization of ion exchanger based on bacterial cellulose for heavy metal cation removal. Egyptian Journal of Chemistry 2019, 62, 457-466, https://doi.org/10.21608/ejchem.2019.12622.1787.

9. Siddiqua, U.H.; Ali, S.; Hussain, T.; Bhatti, H.N.; Asghar, M.J.P.J.o.E.S. The Dyeing Process and the Environment: Enhanced Dye Fixation on Cellulosic Fabric Using Newly Synthesized Reactive Dye. Polish Journal of Environmental Studies 2017, 26.

10. Ibrahim, H.M.; Mostafa, M.; Kandile, N.G. Potential use of N-carboxyethylchitosan in biomedical applications: Preparation, characterization, biological properties. Int. J. Biol. Macromol. 2020, 149, 664-671, https://doi.org/10.1016/j.ijbiomac.2020.01.299.

11. El-Bisi, M.K.; Othman, R.; Yassin, F.A. Improving antibacterial and ultraviolet properties of cotton fabrics via dual effect of nano-metal oxide and Moringa oleifera extract. Egyptian Journal of Chemistry 2020, 63, 3441-3451, https://doi.org/10.21608/ejchem.2020.39534.2805.

12. Salman, A.; Metwally, F.A.; El-Bisi, M.K.; Emara, G.A.M. Effect of geometrical yarn parameters: Conventional and compact ring spinning on certain functional properties of tio2nps treated woven cotton 
fabrics. Egyptian Journal of Chemistry $2020, \quad 63, \quad 1757-1766$, https://doi.org/10.21608/ejchem.2019.18226.2113.

13. Aysha, T.; Zain, M.; Arief, M.; Youssef, Y. Synthesis and spectral properties of new fluorescent hydrazone disperse dyes and their dyeing application on polyester fabrics. Heliyon 2019, 5, https://doi.org/10.1016/j.heliyon.2019.e02358.

14. Akhtar, Z.; Kazmi, M.R.; Ali, S.I.; Abbas, N.; Parveen, R. Application of Acid Dyes on Nylon Fabric and Evaluation of Fastness Properties Part III. Journal- Chemical Society of Pakistan 2018, 40, 898-898.

15. Mohamed, F.A.; Ibrahim, H.M.; Reda, M.M. Eco friendly dyeing of wool and cotton fabrics with reactive dyes (bifunctional) and its antibacterial activity. Der Pharma Chemica 2016, 8, 159-167.

16. Wang, M.; Wang, X.; Guo, C.; Zhao, T.; Li, W. A Feasible Method Applied to One-Bath Process of Wool/Acrylic Blended Fabrics with Novel Heterocyclic Reactive Dyes and Application Properties of Dyed Textiles. Polymers 2020, 12, https://doi.org/10.3390/polym12020285.

17. Aysha, T.; El-Sedik, M.; Abd El Megied, S.; Ibrahim, H.; Youssef, Y.; Hrdina, R. Synthesis, spectral study and application of solid state fluorescent reactive disperse dyes and their antibacterial activity. Arabian Journal of Chemistry 2019, 12, 225-235, https://doi.org/10.1016/j.arabjc.2016.08.002.

18. Hawas, H.S.; Emam, E.A.M.; Tawfik, T.M. Evaluation of the mechanical and functional properties of velvet fabrics treated with fluorocarbon. Egyptian Journal of Chemistry 2020, 63, 3533-3546, https://doi.org/10.21608/ejchem.2020.23461.2391.

19. Ghazal, H.A. Microwave irradiation as a new novel dyeing of polyamide 6 fabrics by reactive dyes. Egyptian Journal of Chemistry 2020, 63, 2125-2132, https://doi.org/10.21608/ejchem.2019.17505.2076.

20. Musa, H.; Abdulmumini, A.; Folashade, M.; Usman, B.; Abba, H. Studies on the Dyeing of Wool and Nylon Fabrics with Some Acid Dyes. Thermodynamics and Kinetics 2013, 5, 11-17.

21. Wang, H.; Lewis, D.J.C.T. Chemical modification of cotton to improve fibre dyeability. Coloration Technology 2002, 118, 159-168.

22. Ibrahim, H.M.; Farid, O.A.; Samir, A.; Mosaad, R.M. Preparation of chitosan antioxidant nanoparticles as drug delivery system for enhancing of anti-cancer drug. In: Key Engineering Materials. KEM, Volume 759, 2018; pp 92-97, https://doi.org/10.4028/www.scientific.net/KEM.759.92.

23. Acharya, S.; Abidi, N.; Rajbhandari, R.; Meulewaeter, F.J.C. Chemical cationization of cotton fabric for improved dye uptake. Cellulose 2014, 21, 4693-4706, https://doi.org/10.1007/s10570-014-0457-2.

24. Sadeghi-Kiakhani, M.; Safapour, S.J.F.; Polymers. Salt-free reactive dyeing of the cotton fabric modified with chitosan-poly (propylene imine) dendrimer hybrid. Fibers and Polymers 2015, 16, 1075-1081, https://doi.org/10.1007/s12221-015-1075-9.

25. El-Alfy, E.A.; El-Bisi, M.K.; Taha, G.M.; Ibrahim, H.M. Preparation of biocompatible chitosan nanoparticles loaded by tetracycline, gentamycin and ciprofloxacin as novel drug delivery system for improvement the antibacterial properties of cellulose based fabrics. Int. J. Biol. Macromol. 2020, 161, 12471260, https://doi.org/10.1016/j.ijbiomac.2020.06.118.

26. Ibrahim, H.M.; Reda, M.M.; Klingner, A. Preparation and characterization of green carboxymethylchitosan (CMCS) - Polyvinyl alcohol (PVA) electrospun nanofibers containing gold nanoparticles (AuNPs) and its potential use as biomaterials. Int. J. Biol. Macromol. 2020, 151, 821-829, https://doi.org/10.1016/j.ijbiomac.2020.02.174.

27. Mosaad, R.M.; Samir, A.; Ibrahim, H.M. Median lethal dose (LD50) and cytotoxicity of Adriamycin in female albino mice. Journal of Applied Pharmaceutical Science 2017, 7, 77-80, https://doi.org/10.7324/JAPS.2017.70312.

28. Seyam, A.F.M.; Hudson, S.M.; Ibrahim, H.M.; Waly, A.I.; Abou-Zeid, N.Y. Healing performance of wound dressing from cyanoethyl chitosan electrospun fibres. Indian Journal of Fibre and Textile Research 2012, 37, 205-210.

29. Nawalakhe, R.G.; Hudso, S.M.; Seyam, A.M.; Waly, A.I.; Abou-Zeid, N.Y.; Ibrahim, H.M. Development of electrospun iminochitosan for improved wound healing application. Journal of Engineered Fibers and Fabrics 2012, 7, 47-55, https://doi.org/10.1177/155892501200700208.

30. Fu, S.; Hinks, D.; Hauser, P.; Ankeny, M.J.C. High efficiency ultra-deep dyeing of cotton via mercerization and cationization. Cellulose 2013, 20, 3101-3110, https://doi.org/10.1007/s10570-013-0081-6.

31. Patino, A.; Canal, C.; Rodríguez, C.; Caballero, G.; Navarro, A.; Canal, J.M.J.C. Surface and bulk cotton fibre modifications: plasma and cationization. Influence on dyeing with reactive dye. Cellulose 2011, 18, 1073-1083, https://doi.org/10.1007/s10570-011-9554-7.

32. Fang, K.; Shu, D.; Liu, X.; Cai, Y.; An, F.; Zhang, X.J.P. Reactive pad-steam dyeing of cotton fabric modified with cationic P (St-BA-VBT) nanospheres. Polymers 2018, 10, https://doi.org/10.3390/polym10060564.

33. Ibrahim, H.M.; Klingner, A. A review on electrospun polymeric nanofibers: Production parameters and potential applications. Polymer Testing 2020, 90, https://doi.org/10.1016/j.polymertesting.2020.106647.

34. Yang, G.; Xie, J.; Hong, F.; Cao, Z.; Yang, X. Antimicrobial activity of silver nanoparticle impregnated bacterial cellulose membrane: effect of fermentation carbon sources of bacterial cellulose. Carbohydr. Polym. 2012, 87, 839-845, https://doi.org/10.1016/j.carbpol.2011.08.079. 
35. Eid, B.M.; El-Sayed, G.M.; Ibrahim, H.M.; Habib, N.H. Durable Antibacterial Functionality of Cotton/Polyester Blended Fabrics Using Antibiotic/MONPs Composite. Fibers Polym. 2019, 20, 2297-2309, https://doi.org/10.1007/s12221-019-9393-y.

36. Mohamed, F.A.; Ibrahim, H.M.; Aly, A.A.; El-Alfy, E.A. Improvement of dyeability and antibacterial properties of gelatin treated cotton fabrics with synthesized reactive dye. Biosci. Res. 2018, 15, 4403-4408.

37. Mohamed, F.A.; Ibrahim, H.M.; El-Kharadly, E.A.; El-Alfy, E.A. Improving dye ability and antimicrobial properties of cotton fabric. J. Appl. Pharm. Sci. 2016, 6, 119-123, https://doi.org/10.7324/JAPS.2016.60218.

38. Cho, K.-H.; Park, J.-E.; Osaka, T.; Park, S.-G. The study of antimicrobial activity and preservative effects of nanosilver ingredient. Electrochim. Acta. 2005, 51, 956-960, https://doi.org/10.1016/j.electacta.2005.04.071.

39. Farouk, R.; Youssef, Y.A.; Mousa, A.A.; Ibrahim, H.M. Simultaneous dyeing and antibacterial finishing of nylon 6 fabric using reactive cationic dyes. World Appl. Sci. J. 2013, 26, 1280-1287.

40. Ibrahim, H.; El- Zairy, E.M.R.; Emam, E.A.M.; Adel, E. Combined antimicrobial finishing dyeing properties of cotton, polyester fabrics and their blends with acid and disperse dyes. Egypt J Chem 2019, 62, 965-976, https://doi.org/10.21608/EJCHEM.2018.6358.1535.

41. Ibrahim, H.; Emam, E.A.M.; Tawfik, T.M.; El-Aref, A.T. Preparation of cotton gauze coated with carboxymethyl chitosan and its utilization for water filtration. J. Text. Appar. Technol. Manag. 2019, 11.

42. Ibrahim, H.M.; Saad, M.M.; Aly, N.M. Preparation of single layer nonwoven fabric treated with chitosan nanoparticles and its utilization in gas filtration. Int. J. Chemtech Res. 2016, 9, 1-16.

43. Ibrahim, N.A.; Kadry, G.A.; Eid, B.M.; Ibrahim, H.M. Enhanced antibacterial properties of polyester and polyacrylonitrile fabrics using Ag-Np dispersion/microwave treatment. AATCC Journal of Research 2014, 1, 13-19, https://doi.org/10.14504/ajr.1.2.2.

44. Mohamed, F.A.; Abd El-Megied, S.A.; Bashandy, M.S.; Ibrahim, H.M. Synthesis, application and antibacterial activity of new reactive dyes based on thiazole moiety. Pigment. Resin Technol. 2018, 47, 246254, https://doi.org/10.1108/PRT-12-2016-0117.

45. Jin, W.-J.; Jeon, H.J.; Kim, J.H.; Youk, J.H. A study on the preparation of poly(vinyl alcohol) nanofibers containing silver nanoparticles. Synthetic Metals 2007, 157, 454-459, https://doi.org/10.1016/j.synthmet.2007.05.011.

46. Ibrahim, H.M.; Zaghloul, S.; Hashem, M.; El-Shafei, A.J.C. A green approach to improve the antibacterial properties of cellulose based fabrics using Moringa oleifera extract in presence of silver nanoparticles. Cellulose 2020, 1-16, https://doi.org/10.1007/s10570-020-03518-7.

47. Ibrahim, H.; Dakrory, A.; Klingner, A.; El-Masry, A. Carboxymethyl Chitosan Electrospun Nanofibers: Preparation and its Antibacterial Activity. Journal of Textile \& Apparel Technology \& Management (JTATM) 2015, 9.

48. Ibrahim, H.M.; Aly, A.A.; Taha, G.M.; El-Alfy, E.A. Production of antibacterial cotton fabrics via green treatment with nontoxic natural biopolymer gelatin. Egyptian Journal of Chemistry 2020, 63, 655-696, https://doi.org/10.21608/ejchem.2019.16972.2040.

49. Farag, S.; Ibrahim, H.M.; Asker, M.S.; Amr, A.; El-Shafaee, A. Impregnation of silver nanoparticles into bacterial cellulose: Green synthesis and cytotoxicity. Int. J. Chemtech Res. 2015, 8, 651-661.

50. Ibrahim, H.M.; El-Zairy, E.M.R. Carboxymethylchitosan nanofibers containing silver nanoparticles: Preparation, Characterization and Antibacterial activity. J. Appl. Pharm 2016, 6, 43-48, https://doi.org/10.7324/JAPS.2016.60706.

51. Li, S.-M.; Jia, N.; Ma, M.-G.; Zhang, Z.; Liu, Q.-H.; Sun, R.-C. Cellulose-silver nanocomposites: Microwave-assisted synthesis, characterization, their thermal stability, and antimicrobial property. Carbohydr. Polym. 2011, 86, 441-447, https://doi.org/10.1016/j.carbpol.2011.04.060.

52. Ibrahim, H.M.; Dakrory, A.; Klingner, A.; El-Masry, A.M.A. Carboxymethyl chitosan electrospun nanofibers: Preparation and its antibacterial activity. Journal of Textile and Apparel, Technology and Management 2015, 9.

53. Annen, O.; Egli, R.; Hasler, R.; Henzi, B.; Jakob, H.; Matzinger, P. Replacement of disperse anthraquinonedyeS. Coloration Technology 1987, 17, 72-85, https://doi.org/10.1111/j.14784408.1987.tb03753.x,

54. Kelemen, J.; Moss, S.; Sauter, H.; Winkler, T. Azo-hydrazone tautomerism in azo dyes. II. Raman, NMR and mass spectrometric investigations of 1-phenylazo-2-naphthylamine and 1-phenylazo-2-naphthol derivatives. Dyes and Pigments 1982, 3, 27-47, https://doi.org/10.1016/0143-7208(82)80011-9. 